\title{
Diffusion pattern of alien invasive plants along Coastal Highway in Liaoning, China
}

\author{
Yan-bo ZHAO ${ }^{1, a^{*}}$, Hong-wei YAN ${ }^{2, b^{*}}$ \\ ${ }^{1}$ College of Horticulture, Shenyang Agricultural University, Shenyang, Liaoning, China \\ ${ }^{2}$ Key Laboratory of Northern Landscape Plants and Regional Landscape, Educational \\ Department of Liaoning Province, Shenyang, Liaoning, China \\ azhaoyb@188.com, byhwwwww@sina.com
}

\begin{abstract}
Keywords: Biological Invasion; Alien Invasive Plant; Diffusion Pattern; Coastal Highway
Abstract. Highway is one of main ways for alien invasive plant dispersal, and the influences of highway on invasive species are more and more concerned by the road ecologists. However, understanding diffusion pattern and invasive mechanism of alien species is the precondition of effective control of their invasion. Line transect method was employed to have an investigation to 4 kinds of wetland types along coastal highway in Liaoning, China. 25 alien invasive species were found. The research indicates that on the gradient from the near to the distant from the highway: (1) richness of invasive plants presents the pattern of first increasing and then decreasing. (2) the frequency of most invasive species at the boundary of highway is significantly higher than that in distant area; some invasive species choose specific wetland types and invade adjacent land; (3) through analyses of standard deviation of important values, some species show great adaptation and strong invasiveness. These pattern indicates that environmental gradient along the highway generates significant influence on plant invasion; It is believed that the species diffusing along the highway generally can adapt the environment at the boundary of highway; while the species diffusing vertically to the highway cannot just adapt coastal wetland environment, but also own strong dispersal ability.
\end{abstract}

\section{Introduction}

Highway is one of main ways for alien plant dispersal. The carrying function of transportation tools provides an opportunity for dispersal of weed and alien plants. Microclimate environment along the highway is characterized by high light, high temperature, large wind and special soil conditions and offers appropriate environmental conditions for growth and development of alien plants. Particularly, after these alien plants succeed in settling down and form certain population advantage, they will diffuse to the peripheral area, change species composition and distribution of plants on adjacent land ${ }^{[1-3]}$. Further, they influence structure and function of the whole ecological system. Hence, the study on the influence of highways on alien plants has become one of research hotspots of contemporary ecology $y^{[4,5]}$.

Understanding diffusion pattern and invasive mechanism of alien species is the precondition of effective control of their invasion, and of sustainable management of environment. Liaoning Coastal Highway is hailed as the longest coastal road in the whole country ${ }^{[6,7]}$. The area along the highway have inevitably been suffering certain ecological influence, incluing the threat by alien plants.

\section{Overview of research area}

Starting from Suizhong County in Huludao in the west and ending at Donggang City in Dandong in the east, Liaoning Coastal Highway connects 6 coastal municipalities directly under the provincial government and 7 county-level municipalities with a total length of $1443 \mathrm{~km}^{[8]}$. Formally put in use in September 2009, it crosses 2 latitude and 5 longitudes, with an altitude of 2 485 m, annual average temperature $9^{\circ} \mathrm{C}$, annual average precipitation $540-1200 \mathrm{~mm}^{[9]}$, annual evaporation capacity 1200-1900 mm and coastal average wind speed over years $3-5 \mathrm{~m} / \mathrm{s}(10 \mathrm{~m} \text { height })^{[10]}$. 


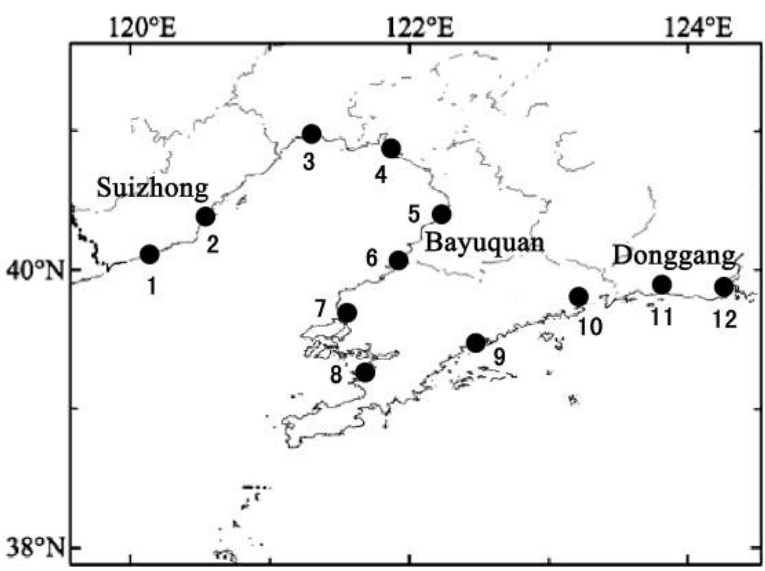

Fig. 1. Position of investigated section

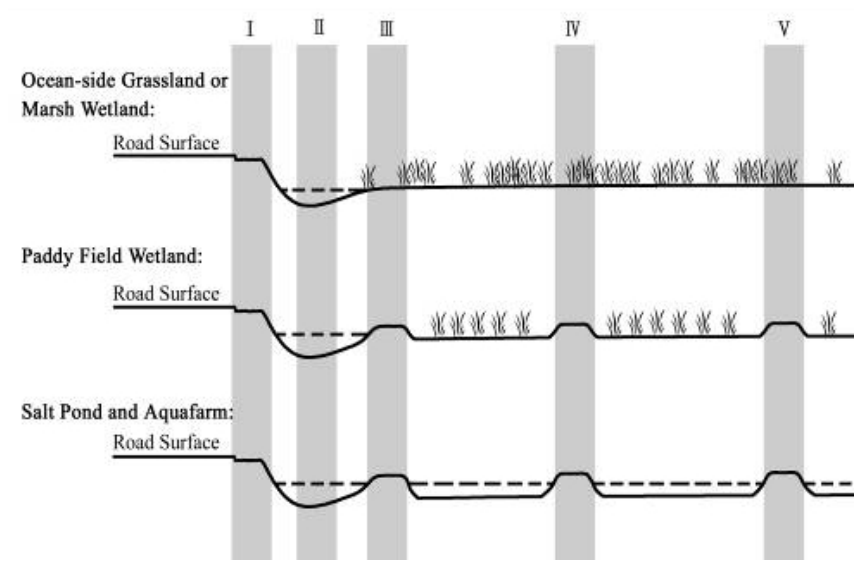

Fig. 2. Cross section of each type of wetland

According to the data and artificial judgment ${ }^{[11-13]}$, in the natural plant communities along the coastal highway, the ocean-side grassland dominated by gramineous weeds such as Aeluropus littoralis var. sinensis and the marsh wetland dominated by Phragmites communis and Typha orientalis are most typical; while the large-area paddy field, salt pond and aquafarm have constituted the main artificial wetland types along the highway.

\section{Research method}

Investigation method. The investigation was concentrated in May to August, 2014. Along the highway, 12 investigated sections were field with ocean-side grassland and marsh wetland representing the type of natural wetland, paddy field wetland and salt pond \& aquafarm representing the artificial wetland type, which covered the 4 types of wetlands above and were distributed along the highway with equal spacing as far as possible (Figure 1, Table 1).

Table 1. Basic information of investigated section

\begin{tabular}{|c|c|c|}
\hline $\begin{array}{l}\text { Investigated } \\
\text { section }\end{array}$ & Type of wetland & Communities overview \\
\hline $4,7,10$ & Ocean-side grassland & $\begin{array}{l}\text { Constructive species include Aeluropus littoralis var. sinensis and } \\
\text { Suaeda glauca, companion species include Asparagus brachyphyllus } \\
\text { Euphorbia humifusa and Phragmites communis with a total coverage } \\
40-80 \% \text {. }\end{array}$ \\
\hline $3,11,12$ & Marsh wetland & $\begin{array}{l}\text { Constructive species include Phragmites communis, Typha orientalis } \\
\text { and Scirpus tabernaemontani and Echinochloa caudate, companion } \\
\text { species include Suaeda glauca, Carex raddei and Zizania latifolia } \\
\text { with a total coverage } 60-90 \% \text {. }\end{array}$ \\
\hline $5,6,9$ & Paddy field wetland & $\begin{array}{l}\text { There are basophilous weeds like Hydrilla verticillata, Cyperus } \\
\text { difformis usually on the dikes and in the field. }\end{array}$ \\
\hline $1,2,8$ & Salt Pond \& aquafarm & There are some weeds growing on the dikes. \\
\hline
\end{tabular}

Line transect method was employed to investigate each investigated section. 3 transects were arranged vertical to the highway in each section and facing the sea, with an interval of $1 \mathrm{~km}$. Quadrats were arranged on the transects, respectively located in road shoulder (I), side ditch (II), slope outside the side ditch (III), $50 \mathrm{~m}$ from the curb (IV), 100m from the curb (V) and 200m from the curb ( $\square$ ) (Figure 2), and 5 sub-quadrats were taken parallel to the road. The quadrat was $1 \mathrm{~m} \times 1 \mathrm{~m}$ in size in principle, but quadrats of $0.5 \mathrm{~m} \times 2 \mathrm{~m}$ on the narrow road shoulder and dikes. Plants species in the quadrats, number and coverage of each species were recorded.

Statistical analysis. Richness index (S) is used to reflect species number of invasive plants; frequency $(F)$ is used to reflect distribution pattern of invasive species; importance value (I.V.) is adopted to evaluate the position and function of invasive species in communities ${ }^{[14,15]}$. 
I.V. $=1 / 3$ (relative frequency + relative coverage + relative density)

25 species of invasive plants are discovered in 216 quadrats of 12 sample sections. The important values (I.V.) of every species of invasive plants in 216 quadrats are calculated respectively, and SPSS19.0 is used to analyze their standard deviations (SD).

\section{Result and analysis}

Species composition of invasive plants. Through sorting and analyzing survey data, 109 species are gained (including 107 herbaceous species and 2 woody species). 25 alien invasive species belong to 12 families and 21 genera (see Table 2). Among these species, the number of the species belongs to Asteraceae are the most (7 species), followed by Amaranthaceae and Poaceae (4 species, respectively). This indicates the possibility of dispersal of species belongs to Asteraceae with highway construction and operation is larger than other families. This is closely related to features of plants of Asteraceae, including large quantity of seeds, light weight, pappus and diffusion with wind or diffusion through being attached to people, livestock or goods. These invasive plants come from various places in the world. 17 species are originally produced in America, accounting for $68 \%$ of total number, and other plants come from Europe, Africa and Asia etc. This indicates weeds in America can well adapt the habitat along highway. Hence, the plans from America mostly likely become invasive plants in this region.

Table 2 Species of alien invasive plants along the highway and std. deviation of their important values (I.V.)

\begin{tabular}{|c|c|c|c|c|}
\hline Scientific name & Family & Origin & Mean of I.V. & Std.Deviation \\
\hline Amaranthus retroflexus & Amaranthaceae & tropical America & 5.2593 & 4.5707 \\
\hline A.virdis & & tropical Africa & 5.7778 & 4.5562 \\
\hline A.tricolor & & India & 0.2963 & 0.6688 \\
\hline A.blitoides & & North America & 0.2593 & 0.4466 \\
\hline Conyza canadenis* & Asteraceae & North America & 15.0370 & 8.8556 \\
\hline Erigeron annuиs* & & Mexico & 16.7778 & 10.6169 \\
\hline Ambrosia artemisiifolia* & & North America & 12.5926 & 10.6169 \\
\hline A.trifida* & & North America & 12.7612 & 11.7869 \\
\hline Galinsoga parviflora & & South America & 1.4444 & 2.2589 \\
\hline Solidago Canadensis* & & North America & 8.2593 & 9.7017 \\
\hline Cichorium intybus & & Europe & 1.6296 & 3.2362 \\
\hline Chenopodium hybridum $* *$ & Chenopodiaceae & Europe and western Asia & 0.2593 & 0.4466 \\
\hline Convolvulus arvensis** & Convolvulaceae & Europe & 0.2963 & 0.6688 \\
\hline Pharbitis purpurea** & & tropical America & 0.0578 & 0.1033 \\
\hline Melilotus alba & Leguminosae & Europe and western Asia & 1.0741 & 2.1826 \\
\hline hibiscus trionum & Labiatae & Africa & 1.3704 & 2.7756 \\
\hline Plantaga lanceolata** & Plantaginaceae & Europe & 0.3274 & 0.6143 \\
\hline Lepidium densiflorum $* *$ & Brassicaceae & North America & 0.3141 & 0.6289 \\
\hline Oenothera biennis $* *$ & Onagraceae & North America & 0.2533 & 0.4563 \\
\hline Azolla filiculoides & Azollaceae & America & 1.0741 & 2.1826 \\
\hline Buchloe dactyloides & Poaceae & North America & 1.0741 & 1.8590 \\
\hline Lolium temulentum & & North America & 1.4444 & 2.7363 \\
\hline Hordeum jubatum $* *$ & & North America & 0.2332 & 0.4576 \\
\hline Spartina anglica* & & Europe & 8.7037 & 14.0324 \\
\hline Sagittaria graminea & Alismataceae & tropical America & 1.5556 & 2.0631 \\
\hline
\end{tabular}

Note: Std. Deviation: Standard deviation of I.V. of this species in quadrats;

* Represents the first category; ** represents the second category; others represent the third category.

Changes in richness of invasive species. Here, richness refers to the number of invasive species which appear within the same gradient in the same wetland type. Fig.3 reflects the richness change trend with the change in the gradient. It can be seen that the total amount of invasive species in all kinds of wetlands presents the pattern of first increasing and then decreasing. The peak is located at outer slope surface of side ditch ( 15 species appear in paddy field wetland). Then, with the rise in the distance with the highway, richness gradually reduces. This shows the change in environmental gradient along the highway generates significant effects on alien plant invasion. The outer slope surface of side ditch 
may suffer alien plant invasion most easily, because this part is near to the highway and has relatively wide soil moisture range. When alien plants invade the inland outward the highway, richness gradually reduces due to the restriction of biological characteristics and competition against with local plant.

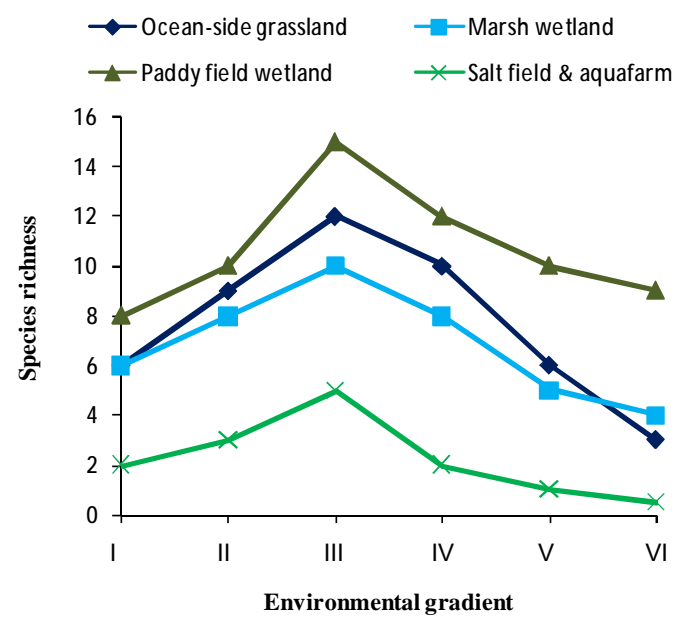

Fig.3 Richness change with the gradient

Frequency of invasive species. It is obviously found in field investigation that some invasive species only appear in the boundary part of adjacent road, i.e. diffuse along the road. Other plants seldom appear near the road, but invade in adjacent land, i.e. diffuse perpendicularly to the road. Through analysis of frequency of invasive species on different gradient, it is found that the frequency of most invasive plants at the road boundary is significantly higher than that in distance area (take Amaranthus retroflexus as an example, see Fig.4). Frequency change of few invasive species is unrelated to gradient or the change is not significant. This explains biological characteristics of most invasive species adapt road boundary environment, but do not adapt coastal wetland environment. Therefore, they can just diffuse along the highway. Such invasive species include Amaranthus retroflexus, A. virdis, Ambrosia artemisiifolia, A. trifida, Melilotus alba, Plantaga lanceolata, Buchloe dactyloides and so on.

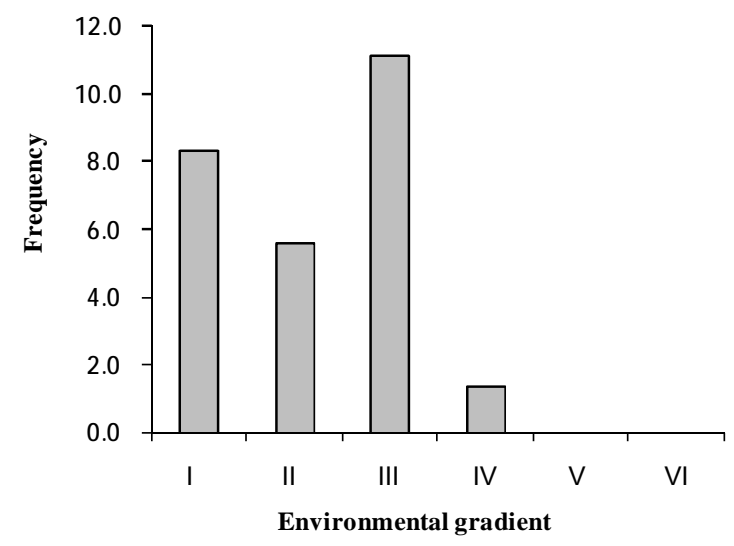

Fig.4 Frequency change of invasive species within different gradient

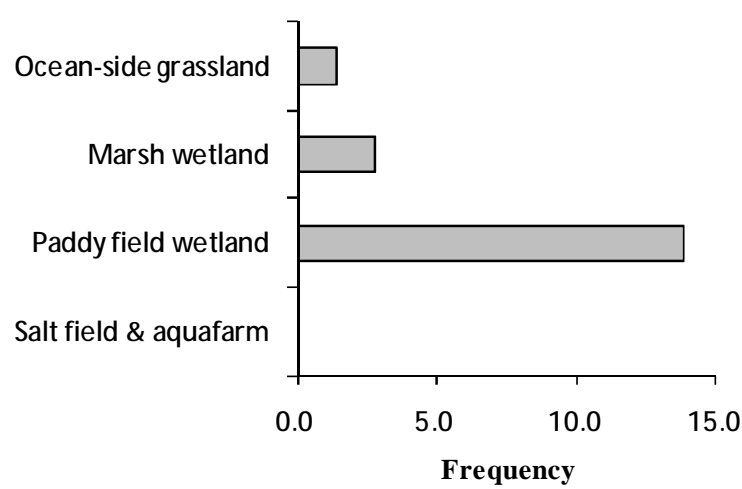

Fig.5 Frequency change of invasive species in different wetlands

It is found through analysis of frequency of invasive species in different wetlands that some invasive species just select specific wetland types and invade in the adjacent land, while these species do not appear or rarely appear in other wetland types (take Erigeron annuus as an example, see Fig.5). This indicates biological characteristics of few invasive species adapt coastal wetland environment, so they can invade in the wetland. Such invasive species include Conyza canadenis, Erigeron annuus, Solidago canadensis, hibiscus trionum, Azolla filiculoides, Lolium temulentum, Spartina anglica, Sagittaria graminea and so forth.

Evenness of invasive species. Since there are great environmental differences along highway and biological characteristics of different species also have large discrepancies, alien invasive plants are distributed unevenly along the whole route. Although richness of invasive plants is no high in some 
sections, coverage and density in the community are very large. The analysis results of $S D$ of $I . V$. of invasive plants in 216 quadrats show that evenness of 25 species of alien invasive plants along the whole route may be roughly classified into 3 categories (see Table 2).

The first category includes 6 invasive species, they are Ambrosia artemisiifolia, A. Trifida, Conyza canadenis, Erigeron annuus, Solidago canadensis, and Spartina anglica. Although they own broad ecological niche, their coverage and density in each invasion place are greatly different due to environmental influence. This shows their very strong invasion characteristic. Ambrosia artemisiifolia and A. Trifida are mainly distributed at the road shoulder and outer slope surface of side ditch along the highway. Conyza canadenis, Erigeron annuus and Solidago canadensis often appear in grassland and the ridge of paddy field, while Spartina anglica is mainly distributed in paddy field and aqua-farm.

The second category includes 9 species, they are Amaranthus tricolor, A. Blitoides, Chenopodium hybridum, Convolvulus arvensis, Pharbitis purpurea, Plantaga lanceolata, Lepidium densiflorum, Oenothera biennis and Hordeum jubatum. Their important values in the whole quadrats are very low. Besides, the differences in important values are not significant.

Other 10 species of invasive plants can be boiled down to the third category. They mostly belong to the species with wide distribution. They are distributed evenly in the quadrats, and their important values are not very high. Meanwhile, the differences in important values are not great.

\section{Conclusion and discussion}

First of all, this paper identifies alien species and confirms 25 species of invasive plants. Then, richness change reflects the general trend of invasive species diffusion. Frequency analysis reflects the direction of invasive species diffusion. Evenness analysis further differentiates the influence degree of invasive species on ecological system.

Seeing from richness change, the total number of alien species presents the pattern of first increasing and then decreasing. This explains environmental gradient along the highway imposes signifies impacts on alien plant invasion. The boundary part nearest to the highway is the direct reception surface of various road pollutants, so it may be invaded by alien species most easily. On the gradient far away from the highway, because invasive species are restricted by coastal wetland environment, few species can invade inland.

Just because environmental conditions of each gradient are diverse, invasive species present different distribution rules. Most invasive species can adapt road boundary environment and diffuse along the road, because they adapt relatively high-temperature, dry and barren soil environment. such plants are dominated by Amaranthus and Ambrosia. Few invasive species select specific wetland types to invade in the adjacent land and diffuse to the inland perpendicularly to the highway, because they not just adapt coastal wetland environment, but own strong propagation ability and dispersal ability. For example, Conyza canadenis and Erigeron annuus which can generate a large number of achenes and diffuse with the wind under the help of pappus. The grass such as Spartina anglica with saline-alkaline tolerance and very strong conidial capacity is in the absolute predominance in competitions. Such grass will be bound to invade in coastal wetland.

The occurrence frequency of invasive species can reflect their distribution in the research area, but cannot be used to predict their development trend along the highway. It is still necessary to evaluate the position and function of species in the community with importance values in order to know development situation of invasive species along the highway. In general, Conyza canadenis, Erigeron annuus and Spartina anglica own very strong competitive ability and diffusion ability and cause a serious threat to biodiversity and ecological system stability along highway. So, it is required to attach importance to them and take prevention measures.

In conclusion, only when the diffusion pattern of invasive plants is really grasped, targeted prevention and treatment countermeasures can be found out. In addition, this has certain guiding significance for greening and ecological recovery along the highway. 


\section{Acknowledgments}

Supported by Project of National Natural Science Foundation of Liaoning Province(20102200).

\section{References}

[1] Yue-hui Li, Yan-man HU, Yu CHANG, Xiu-zhen Li, Ren-cang Bu, et al, Effect zone of forest road on plant species diversity in Great Xing'an Mountians, Chinese Journal of Applied Ecology, 21( 2010) 1112-1119.

[2] L.A. Parends, J.A. Jones, Role of light availability and dispersal in exotic plant invasion along roads and streams in the H. J. Andrews Experimental Forest, Oregon, Conservation Biology. 14(2000) 64-75.

[3] P.G. Angold, The impact of a road upon adjacent heath-land vegetation: effects of plant species composition, Journal of Applied Ecology. 34 (1997) 409-417.

[4] R.T.T. Forman, Road ecology: A solution for the giant embracing us, Landscape Ecology. 13 (1998) iii-v.

[5] Chang-qun DUAN, Advances in Ecological Sciences, 5th ed., Higher Education Press, Beijing, 2010.

[6] Si-yu QIN, The longest coastal highway in China, places names along Liaoning Coastal Highway were shining, China Geographic Name. 5 (2011) 52-61.

[7] An XIAO, Liaoning Coastal Highway had opened to the traffic officially which was honoured as the longest coastal highway in China, Road Machinery \& Construction Mechanization. 11 (2009) 1-2.

[8] Yan-ying BO, The significance of the extension of coastal highway, Liaoning Daily, 2006-3-27(003).

[9] Wei-ling LIU, Jing-hai ZHU, Yuan-mang HU, Zhi-hua LIU, Impacts of Road Construction on Ecosystems alongside Coastal Highway in Liaoning Province, Environmental Protection Science. 34(2008) 82-85.

[10] Qiang GONG, Guo-en YUAN, Hong-yu WANG, Na LIN, Hua-shen YU. State and Exploitation Potentiality of Wind Energy Resources in Liaoning Littoral, Scientia Geographica Sinica. 26(2006) 483-489.

[11] Bo-ying LI, Evaluation of Wetland Ecosystem Health of the Coastal Wetland in Liaoning Province, MS thesis, Liaoning Normal University, Shenyang, 2012.

[12] Ya-xing WEI, Li-wen WANG, Jun YANG, Study on Coastal Wetland of Liaoning Province Based on Remote Sensing and Geographic Information System, Geomatics \& Spatial Information Technology. 33(2010) 1-3.

[13] Hua ZHANG, Li-yuan ZHANG, Jie FU, Xu KANG, Types of Coastal Wetlands and Its Value of Ecosystem Service in Liaoning Province, Wetland Science. 7 (2009) 342-350.

[14] Ke-ping MA, The measurement of community diversity, in: Ying-qian QIAN and Ke-ping Ma (Eds.), Principle and Methodologies of Biodiversity Studies, Chinese Science and Technology Press, Beijing, 1994, pp. 141-165.

[15] Jin-tun ZHANG, Quantitative Ecology, 2nd ed., Science Press, Beijing, 2011. 